\title{
Effect of platelet mediator concentrate (PMC) on Achilles tenocytes: an in vitro study
}

\author{
Esra Arslan ${ }^{1,2}$, Thomas Nellesen ${ }^{1}$, Andreas Bayer ${ }^{3}$, Andreas Prescher ${ }^{4}$, Sebastian Lippross ${ }^{5}$, Sven Nebelung ${ }^{6}$, \\ Holger Jahr ${ }^{6}$, Christine Jaeger ${ }^{7}$, Wolf Dietrich Huebner ${ }^{7}$, Horst Fischer ${ }^{8}$, Marcus Stoffel ${ }^{9}$, Mehdi Shakibaei ${ }^{10}$, \\ Thomas Pufe ${ }^{1}$ and Mersedeh Tohidnezhad ${ }^{1 *}$
}

\begin{abstract}
Background: Although there are many studies discussing the etiological and pathological factors leading to both, acute and chronic tendon injuries, the pathophysiology of tendon injuries is still not clearly understood. Although most lesions are uncomplicated, treatment is long and unsatisfactory due to the poor vascularity of tendon tissue. Platelet mediator concentrate (PMC) contains many growth factors derived from platelets, which can promote wound healing. In this study we investigate the effects of PMC on tenocyte proliferation and differentiation in order to provide an experimental basis for tissue regeneration strategies and to develop new treatment concepts.

Methods: Using enzyme linked immunosorbent assay (ELISA) we were able to quantify the several growth factors and cytokines found in PMC. Tenocytes were isolated both from human and from mouse Achilles tendons and stimulated with PMC. CyQuant ${ }^{\oplus}$ and Cell Titer Blue ${ }^{\oplus}$ assays were carried out to analyze tendon growth and viability at different concentrations of PMC. Real time RT-PCR was used to analyze tenocyte gene expression with or without PMC treatment. Immunohistochemistry was carried out to detect the tenocyte-specific antibody tenomodulin (TNMD) and scleraxis (SCX).

Results: We were able to detect numerous mediators such as platelet derived growth factor BB (PDGF-BB), interleukin 6 (IL-6), vascular endothelial growth factor (VEGF), tumor necrosis factor (TNF-a), transforming growth factor beta 1 (TGF-B1), and bone morphogenetic proteins 2, 4 and 7 (BMP-4, BMP-2, BMP-7) in PMC. It was possible to show a positive effect of PMC on human tendon cell growth and viability in a dose-dependent manner. Furthermore, PMC treatment led to induction of gene expression of scleraxis (SCX), type I collagen A 1 (Col1A1) and TNMD by tenocytes.
\end{abstract}

Conclusions: We suggest that the use of autologous PMC may be a suitable addition to conventional tendon therapy that is capable of increasing and optimizing tendon healing and reducing the risk of recurrence.

Keywords: Tenocyte, Platelet, Platelet mediator concentrate, Scleraxis, Tenomodulin

\footnotetext{
* Correspondence: mtohidnezhad@ukaachen.de

'Department of Anatomy and Cell Biology, RWTH Aachen University,

Wendlingweg 2, D-52074 Aachen, Germany

Full list of author information is available at the end of the article
} 


\section{Background}

Between three and five million people worldwide suffer tendon and ligament injuries every year [1]. Achilles tendinopathy is often related to specific sports injuries caused by inappropriate biomechanical stress. It can also occur through non-usage due to sedentary lifestyles. Furthermore the occurrence in association with metabolic disorders such as arthritis and diabetes, or from the use of medications such as corticosteroids or certain antibiotics, underscores the multifactorial etiology of tendinopathy [2].

Tendon ruptures are classified as either spontaneous, traumatic, or open laceration. Previous histological examinations of spontaneously ruptured Achilles tendons have elucidated degenerative changes in a majority of cases [3]. Degenerative changes in the Achilles tendon emerge primarily in regions with hypo- or avascularity, such as at the insertion or tendon-waist [4]. Multiple microtrauma lead to high expression of VEGF, which is characteristic of the painful pathogenesis of tendon ruptures [5]. VEGF-mediated neoangiogenesis is found in areas with neovessels and accompanying nerves together with synthesis of matrix metalloproteinases (MMP) [6].

VEGF is not the only molecule to regulate tendon development and healing. Others include SCX, PDGF-BB and TGF- $B 1$ [7]. In general, growth factors play an important role in the several phases of tendon healing. There is an inflammatory, a proliferative, and a remodeling phase [7].

Tendon ruptures are currently managed either conservatively or surgically [8]. Regardless of treatment method, however, there is no guarantee that full function can be regained, and a recurrence risk after surgical treatment persists $(1.7-5.4 \%)[9,10]$. The ability of tendons to self-repair is limited. Treatment is thus long and unsatisfactory, and only $70 \%$ of patients regain full previous tendon function [10]. Repaired tendon characterized by scarring, and its biomechanical properties are altered and inferior [11].

New approaches to treatment employ alternative strategies such as stem cell repair, platelet rich plasma (PRP) or other orthobiologics, either through direct application or in conjunction with scaffolding $[1,12,13]$. Studies indicate that autologous growth factors, in the form of PRP, have an accelerated curative effect especially in treating ruptured Achilles tendons [14-16]. PRP delivers local autologous bioactive agents which influence the tendon healing phases, inflammation, extracellular matrix (ECM) synthesis and angiogenesis [17]. Plateletreleased growth factors (PRGF) have a similar effect. This is a concentrated form of platelets without both erythrocytes and leukocytes [16].

However, there is no standardized method of plasma preparation. Randomized clinical trials are few [13]. The Advanced Tissue Regeneration Kit (ATR ${ }^{\circ}$ ) manufactured by Curasan AG Kleinostheim offers a standardized, laborfree approach. It delivers a centrifugation-free method of preparing human platelet mediator concentrates (PMC) [18]. The kid can be used chairside in the visiting room and is ready in a few hours. The present study detects different mediators in PMC and compares then with plasma and serum. Furthermore the effects of PMC on human and mouse tenocytes are elucidated in vitro.

\section{Methods}

Substantial growth factors were detected and quantified in PMC. The levels of these growth factors in PMC were compared to those of plasma and serum. The PMC were used as stimuli to treat tenocytes.

\section{PMC preparation}

The $\mathrm{ATR}^{\circ}$ kit is a sterilized, disposable medical product. PMC were prepared as described in the guide and other work by Schmolz et al. [18]. First $8 \mathrm{ml}$ whole peripheral blood from healthy, mainly male donors between the ages of 20-35 was drawn into a $10 \mathrm{ml}$ syringe. There it was mixed with a combination of an anticoagulant and a sedimentation accelerator (Solutions $\mathrm{A}$ and B). This blood mixture rests for approximately 50 to $60 \mathrm{~min}$ in an upright position as provided for by the kit, at room temperature. The plasma supernatant containing the platelets was then transferred into a $5 \mathrm{ml}$ syringe. $3.5 \mathrm{ml}$ supernatant was then injected into the top opening of the ATR system, where the platelets pass through different filter systems. Solution C, which contains a washing buffer, was then added. It eliminated any anticoagulants or sedimentation fragment. Solution D was the last to be injected. It has triggerd the release of mediators from the platelets. The injection proceed in two steps. First $1 \mathrm{ml}$ of solution $\mathrm{D}$ was added and incubated at room temperature for $10 \mathrm{~min}$. Then the rest of the solution was pressed onto the filter. The triple-concentrated PMC, containing only the mediators, was collected at the lateral opening of the kit using another syringe. We aliquoted the PMC in $200 \mu \mathrm{L}$ Eppis and stored it at $-80{ }^{\circ} \mathrm{C}$.

\section{Serum and plasma preparation}

Blood from 14 human volunteers (18-45 years, 5 male, 9 female) was collected, from which whole blood $(10 \mathrm{ml})$ was kept to clot at room temperature for approximately $10 \mathrm{~h}$ and centrifuged at $2,000 \times \mathrm{g}$ for $10 \mathrm{~min}$ at $37^{\circ} \mathrm{C}$ to the serum. Plasma was prepared from whole blood from same volunteers in a second syringe containing anticoagulant (citrate) and centrifuged in the same way. Each serum and plasma sample was stored in aliquots at $-20{ }^{\circ} \mathrm{C}$ until further use (i.e., ELISA analyses).

\section{Isolation of human tenocytes}

Tenocytes were isolated from the Achilles tendon of postmortem human donors under written declarations of consent obtained from each donor enrolled in this 
study; these are on record at the Department of Anatomy. The tendon was washed with phosphate buffered saline (PBS) and cut into pieces after careful removal of the epitendineum. To remove the fibroblasts, the tissues were pretreated with $0.5 \%$ trypsin for 5 min at $37{ }^{\circ} \mathrm{C}$. Subsequently, the tendon pieces were washed and cultivated in Dulbecco's modified Eagle's medium (DMEM) $\left(\mathrm{GIBCO}^{\circ}\right.$, Invitrogen) containing $50 \%$ fetal calf serum (FCS) and $1 \%$ penicillin streptomycin Fungizone (PSF) [19]. After approximately two weeks, tenocytes continuously migrated from this explant and adhered to petri dishes. After 70-80 \% confluence, cells were removed using $1 \%$ trypsin (5x; Gibco, Invitrogen) and cultivated in culture medium (DMEM) $\left(\mathrm{GIBCO}^{\circ}\right.$, Invitrogen) containing $100 \mathrm{unit} / \mathrm{ml}$ penicillin, $100 \mu \mathrm{g} / \mathrm{ml}$ streptomycin $\left(\mathrm{GIBCO}^{\circ}\right.$, Invitrogen) and $10 \% \mathrm{FCS}$. The tenocytes were used from the second through fourth passages.

\section{Isolation of mouse tenocytes}

Tenocytes were isolated from the Achilles tendons of mice between two and three days after birth (balb/mouse; charles river). First, the skin and epitendineum were carefully removed from the Achilles tendon. Tissue was segmented and treated with $1 \%$ trypsin (5x; Gibco, Invitrogen) for five minutes at $37{ }^{\circ} \mathrm{C}$. After washing with $\mathrm{PBS}$, the tendon was cultivated in culture medium containing $50 \%$ FCS [20]. The concentration of the FCS was reduced to $10 \%$ FCS after one week. After two weeks cultivation, a $70-80 \%$ confluence had been achieved. Passaging was then performed with $1 \%$ trypsin in PBS.

\section{Stimulation of cells with PCM}

After the second passage, the adherent monolayer was trypsinized and seeded in Petri dishes at $10^{5}$ cells $/ \mathrm{cm}^{2}$ cells, and then cultivated in culture medium. One day prior to stimulation, the concentration medium was replaced by serum-starved medium containing $1 \%$ FCS. Stimulation with PMC ensued at concentrations of 0,1 , 5 and $10 \%$ in FCS starved medium for $3 \mathrm{~h}$ and $24 \mathrm{~h}$.

\section{Cell proliferation and cell viability assay}

The CyQuant ${ }^{\circ}$ assay Kit (Invitrogen GmbH, Darmstadt, Germany) was employed to measure in vitro tenocyte cell proliferation according to the manufacturer's protocol. The CellTiter-Blue ${ }^{\circ}$ Cell viability assay (Promega Corporation, Madison, USA) was used to evaluate cell viability in response to various concentrations of PCM. Human tenocytes treated according to the stimulation protocol above were used for both assays. The results were normalized to control group without PMC addition.

\section{Analysis of mediator composition of PMC}

The concentrations of different mediators like PDGFBB, VEGF, TGF- $\beta 1$, BMP-2, BMP-4, BMP-7, TNF- $\alpha$ and
IL-6 were assessed in PCM, serum and plasma using commercially available ELISA kits (R\&D Systems and Peprotech).

\section{Real time RT-PCR}

RNA was extracted with NucleoSpin RNA XS (Machery Nagel, Germany) according to the manufacturer's protocol. The RNA concentration was determined by photometric analysis using the NanoDrop 1000 system (PEQLAB Biotechnologie $\mathrm{GmbH}$ ). $1 \mu \mathrm{g}$ of total RNA was then digested with DNase I (Roche $\mathrm{GmbH}$ ) and transcribed into cDNA by reverse transcription with RevertAidTM reverse transcriptase (Fermentas Life Sciences). Real time PCRs were processed in triplicate using the ABI StepOnePlusTM apparatus (Applied Biosystems) in a total volume of $15 \mu \mathrm{l}$ containing 70-100 ng of cDNA, gene specific primers and SYBR Green I reagent (Applied Biosystems). The target genes tenomodulin (TNMD), scleraxis (SCX) and Collagen1A1 (Col1A1) (Qiagen, Germantown, MD, USA) were measured. Beta-2-microglobulin (B2M) served as internal control.

\section{Immunofluorescence}

For immunofluorescence, tenocytes were seeded and cultivated on cover slides. Having been washed thrice with PBS, cells were fixed in Zamboni for $10 \mathrm{~min}$ and washed again with PBS. Cells were stored until use in PBS at $4{ }^{\circ} \mathrm{C}$. The cells were then washed thrice with $0.1 \%$ Triton X in PBS for 5-10 min and then thrice with TRIS for $5 \mathrm{~min}$. Afterwards cells were blocked with $1.5 \%$ bovine serum albumin (BSA) in TRIS for $20 \mathrm{~min}$. Immunostaining against tenomodulin (Santa Cruz Biotechnology, CA, USA; sc-49352) (1:50 in Tris-buffered saline, $2 \mathrm{~h}$ ) and scleraxis (Santa Cruz Biotechnology, CA, USA; sc-49352) (1:50 in Tris-buffered saline, $2 \mathrm{~h}$ ) was used to characterize the differentiated phenotype of the tenocytes. Phalloidin Alexa Fluor 488 (life technologies, A12379, 1:20) and Alexa Fluor 594 (life technologies, A 21431, 1: 350) (1:200 in $1.5 \%$ BSA in TRIS, $2 \mathrm{~h}$ ) was used subsequently. A bisBenzimide staining was used to counterstain the nuclei. To analyze the expression of SCX and TNMD in tenocytes, three (3) images from each sample were captured randomly. Images were made using a Keyence BZ-9000 microscope with a 20× PlanFlour El NA $0.45 \mathrm{Ph} 1$ objective and equal exposure time. Expression of SCX and TNMD were determined using the freely available software FIJI [21]. Contoures of tained cells were followed with the freeform tool to define regions of interest (ROI-1) and their mean grey value was determined. In parallel, the mean grey value of the cell-near background was determined (ROI-2) and substracted from ROI-1 to calculate the mean overall value per picture. The values were normalized to the control group. 


\section{Statistical analysis}

Results were expressed as the mean \pm standard error (SEM) and compared using a one-way ANOVA, Dunnett's post hoc test. To compare the growth factor content of PMC, plasma and serum, we used a one-way ANOVA, Bonferroni test. Differences were considered significant at $p \leq 0.05$. All statistical graphs and analyses were created with GraphPad Prism 5.0 (GraphPad Software, La Jolla, CA, USA).

\section{Results}

Various mediators were detected using ELISA in PMC and compared with serum and plasma (Fig. 1). In PMC the PDGF-BB, hVEGF, TGF- $\beta 1$ and BMP-4 concentrations were substantially elevated as compared to serum und plasma. At the same time the IL- 6 and TNF- $\alpha$ levels were significantly lower than in serum and plasma. Data showed no significant difference in BMP-2 and BMP-7 levels of PMC as compared to plasma and serum.
Cell viability was determined by using a CellTiterBlue $^{\circledast}$ Cell viability assay (Fig. 2). The cell viability rate improved with application of PMC as a media supplement at $3 \mathrm{~h}$ and $24 \mathrm{~h}$. There was no effect after $3 \mathrm{~h}$, but any concentration of PMC tested led to increased cell viability after 24. PMC increased the cell viability of tenocytes positively, in a concentration dependent manner, after $24 \mathrm{~h}(\mathrm{~B})$ of stimulation $(1.0 \pm 0.036,1.41 \pm$ $0.049,1.50 \pm 0.044,1.69 \pm 0.069,1.70 \pm 0.076$ and $1.51 \pm$ 0.043 by $0,1,2.5,5,10$ and $20 \%$ PCM, $n=6, p \leq 0.05$ ); but no effect appeared after $6 \mathrm{~h}$ treatment (A).

The proliferative effect of PMC on human Achilles tenocytes was tested in a CyQuant assay (Fig. 3). PMC concentrations of $0,1,2.5,5,10$ and $20 \%$ were tested. Significantly increased cell proliferation was observed in tenocytes at each PMC concentrations used $(1.00 \pm 0.21$, $1.25 \pm 0.035,1.33 \pm 0.034,1.41 \pm 0.057,1.61 \pm 0.085$ and $1.56 \pm 0.10$ by $0,1,2.5,5,10$ and $20 \%$ PCM, $24 \mathrm{~h}, n=14$, $p \leq 0.05)$.

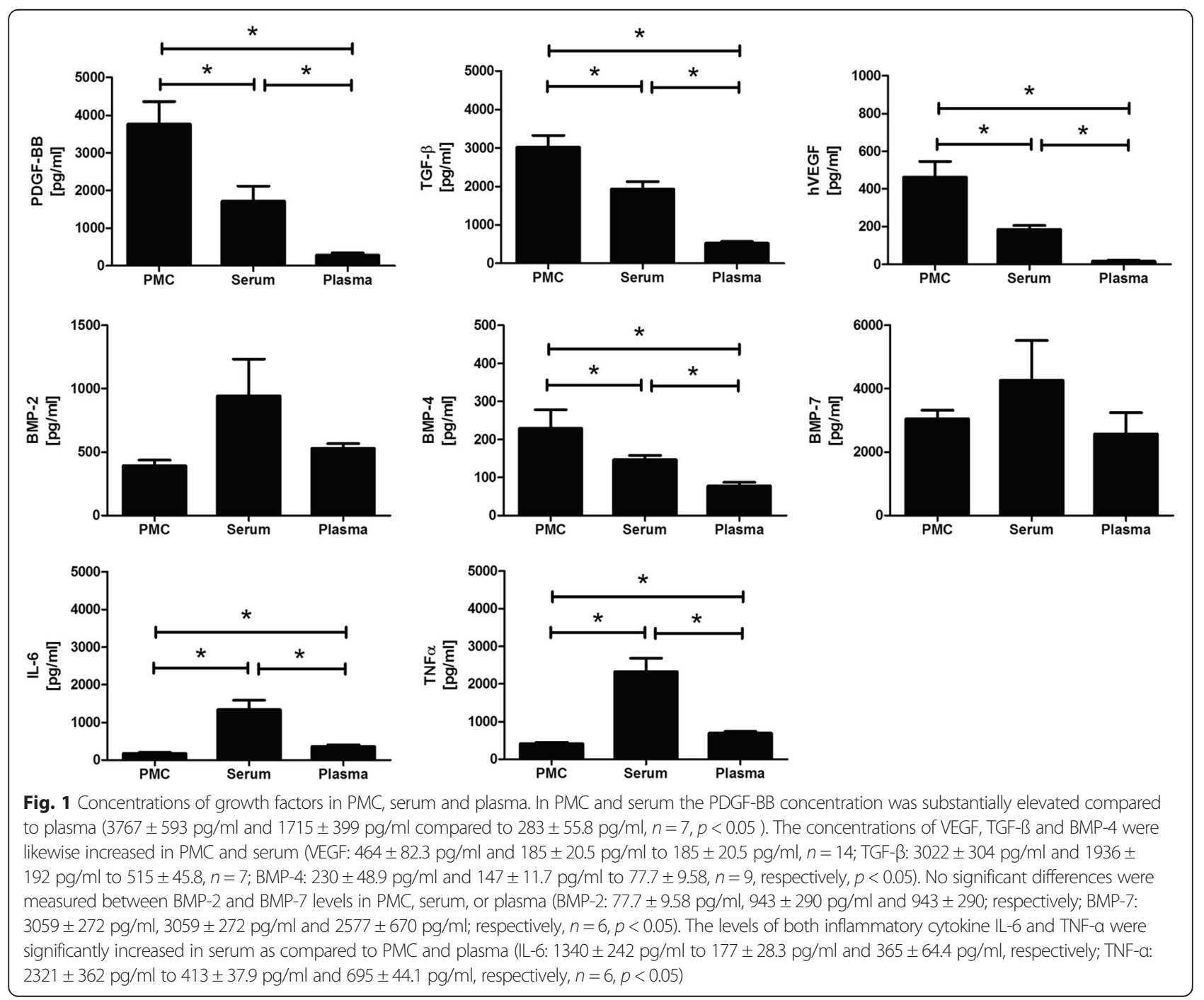



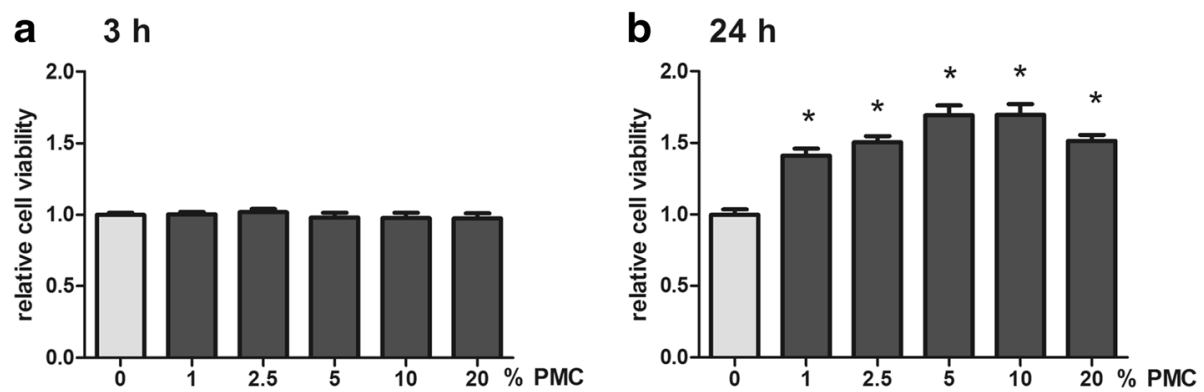

Fig. 2 Cell viability. The cell viability rate was improved by application of PMC to the media. Cell viability was measured using a CTB assay at $3 \mathrm{~h} \mathrm{(a)} \mathrm{and} 24 \mathrm{~h}$ (b). No effect could be discerned after 3 h; but every concentration of PMC tested led to increased cell viability after $24 \mathrm{~h}$

To assess whether PMC influences the tendon-specific gene expression, we used real time PCR. The expression of SCX, COL1 and TNMD genes was determined after treatment with different concentrations of PMC (Fig. 4). Gene expression analysis confirmed a significant induction of these genes only at $1 \%$ PMC $(3.33 \pm 0.48,12.7 \pm$ 6.55 and $2.4 \pm 0.74$ respectively, $n \geq 5, p \leq 0.05$ ).

In order to confirm these results, immunofluorescence was used as a means of assessing the effect of PMC on tenocytes. This analysis revealed an increased relative expression of SCX in tenocytes upon stimulation with $1 \%$ PMC. (The relative $\mathrm{x}$-fold SCX protein expression was $1.33 \pm 0.54$ for $1 \% \mathrm{PMC}, 1.10 \pm 0.07$ for $5 \%$ PMC and $1.04 \pm 0.06$ for $10 \%$ PMC versus $1.0 \pm 0.08$ for the control group, $n \geq 5, p \leq 0.05$.) There was no significant change in TNMD expression after PMC treatment (1.0 \pm 0.03 for $1 \% \mathrm{PMC}, 0.95 \pm 0.03$ for $5 \% \mathrm{PMC}$ and $0.98 \pm$ 0.04 for $10 \%$ PMC versus $1.0 \pm 0.02$ for the control group; $n \geq 5, p \leq 0.05$ ) (Fig. 5).

\section{Discussion}

Many clinical and laboratory results have been published that show positive healing effects of orthobiologics like PRP, stem cells, PRGF, platelet rich fibrin (PRF), and other platelet compositions in tendon repair [22, 23]. Nevertheless, the different methods of preparing various



Fig. 3 Cell proliferation. Tenocyte proliferation increased with PMC concentration. The cell proliferation assay was measured using CyQuant cell proliferation assay at $24 \mathrm{~h}$ platelet compositions do not guarantee the same biological response. This prevents a suitable comparison of results [24] [25]. Because the ATR kit employs a standardized method to deliver a mediator composition, its use allows for mutual comparison of results. Such a standardized method of preparing PMC could provide an alternative means of achieving similar biological effects in patients, particularly in a clinical setting.

The results described above demonstrate that PMC contains most of the important mediators in tendon healing: PDGF-BB, hVEGF, TGF-ß31, BMP-4, BMP-2 and BMP-7. The concentration of the mediators was considerably higher than that found in the plasma and serum. PDGFBB was increased by a factor of 13, hVEGF by a factor of 24 , and TGF- 31 and BMP- 4 each by a factor of 3 .

Prior studies had already shown that PDGF-BB exerts an accelerating effect by stimulating the migration and proliferation of tenocytes and progenitor cells [14]. Recent in vitro studies have also demonstrated the bacteriostatic effect of TGF- $\beta 1$ and PDGF-BB in blood components like PRP [26]. Additionally, TGF-ß1 contributes to the formation of scars as well as fibronectin expression in tendon healing, which is less positive [27, 28]. VEGF, by contrast, appears to have a somewhat harmful effect on in vitro tendon healing as it induces angiogenesis and matrix metalloproteinases (MMPs). It thus downgrades the material properties of the Achilles tendon [6]. However, in chronic wounds characterized by insufficient blood supply, angiogenesis is an important factor to improve healing, particularly during the early phase of tendon healing [29].

This study quantified a low level of TNF- $\alpha$ and IL- 6 in PMC. Prior studies have addressed the importance of various anti-inflammatory factors during the early phase of tendon healing. Most recently Ackermann et al. demonstrated an up-regulation of the anti-inflammatory cytokines IL-6, IL-8 and Il-10 as well as a resolution of the inflammatory phase two weeks after Achilles tendon rupture in humans [30]. Andersen et al. suggest that IL-6 is involved in the transformation of mechanical loading into collagen synthesis [31]. TNF- $\alpha$ is upregulated in tendon 



Fig. 4 Gene expression of SCX, COL1 and TNMD after PMC treatment. Only the addition of $1 \%$ PMC to the tenocyte culture medium showed significantly increased gene expression of the tenocyte specific markers SCX, COL1 and TNMD as compared to 5 and $10 \%$ PMC supplementation (SCX: $3.33 \pm 0.48$ compared to $1.76 \pm 0.16$ and $2.65 \pm 0.90$, respectively $n=5$; COL $1: 12.7 \pm 6.55$ compared to $8.37 \pm 3.75$ and $0.94 \pm 0.22$, respectively, $n \geq 6$, TNMD: $2.7 \pm 0.87$ compared to $0.86 \pm 0.19$ and $0.63 \pm 0.08$, respectively, $n \geq 4, p \leq 0.05$ )

lesions and has been found to be an important regulating factor in that context. It stimulates additional production of the pro-inflammatory cytokines interleukin 1 beta (IL$1 ß)$, TNF- $\alpha$, and anti-inflammatory cytokin IL-10 , whereas its expression is reduced in loaded as compared to unloaded tendon repair [11, 32]. Furthermore TNF- $\alpha$ leads to suppression of type 1 collagen and to extracellular matrix (ECM) degradation through stimulation of MMPs. ECM causes damage and scar formation during tendon healing. Taken together, pro-inflammatory cytokines seem to have both positive and negative effects on tendon healing. As PMC only contains lesser amounts of TNF- $\alpha$, we suggest that it acts as less of a trigger of inflammation after application.

PMC also contains variants BMPs, which have been described as inducing adipogenic, osteogenic and chondrogenic differentiation of mesenchymal stem cells (MSCs) and tendon-derived stem cells (TDSCs) in vitro [33]. The addition of PMC to human Achilles tenocytes leads to a dose-dependent significant enhancement of tenocyte proliferation and viability. Thus we can exclude a toxic response.

Tendon tissues harbor a unique cell population, termed tendon stem/progenitor cells (TSPCs), which has
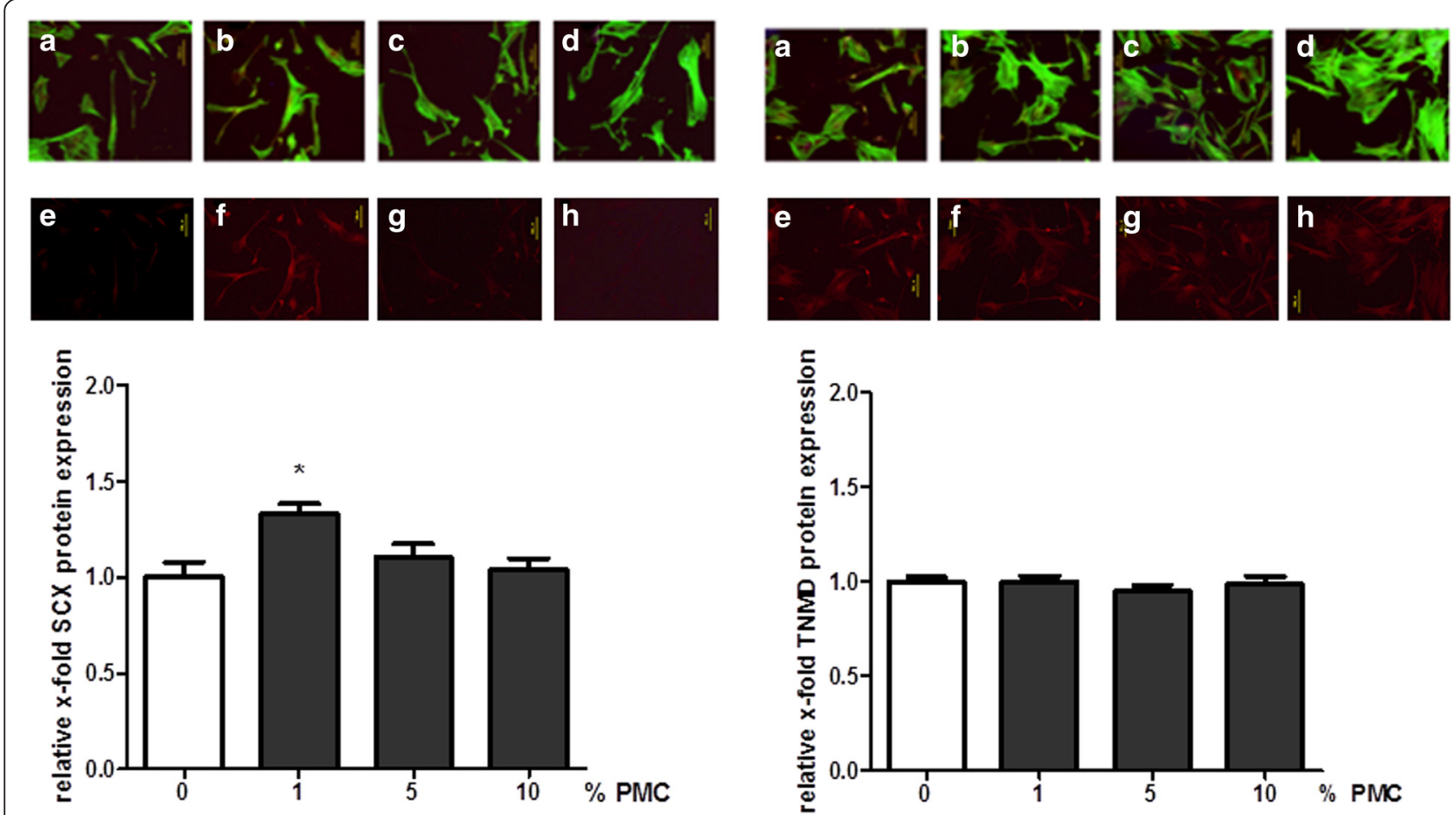

Fig. 5 Protein expression of SCX and TNMD after PMC treatment. Protein expressions of SCX (red) and TNMD (red) were detected using immunofluorescence. Phalloidin staing (green) displayes the cell morphology. The addition of 1 \% PMC to the tenocyte culture medium (b, $\mathbf{f}$ ) showed significantly increased SCX protein expression in tenocytes. There was no effect on TNMD protein expression. Fluorescence intensity was measured and quantified using the software Image J. (a and e: $0 \%, \mathbf{b}$ and f: $1 \%, \mathbf{c}$ and $\mathbf{g :} 5 \%$, d and h: $10 \%$ PMC) 
universal stem cell characteristics such as self-renewal capacity. The effect of PMC on TSPCs is not clear [34].

Another major advantage of PMC is that it only involves mediators without foreign antigens (e.g., blood group antigens, HLA molecules) such as may cause an immunogenic responses [18]. The great importance of this is shown in an unpublished paper within our task group proving the apoptotic effect of platelet poor plasma (PPP) on cells, where the addition of a minimal quantity of PRP eliminated the condition. Using real time RT-PCR we were able to quantify the expression of the tendon-typical genes TNMD, SCX and Col1A1 following treatment of mouse tenocytes with PMC. Tendons are naturaly a largely avascularized tissue and under physiological condition a high amount of blood-derived growth factors may not be required. We could show that lower concentrations of PMC are more effective in inducing tenogenic marker gene expression than higher amounts PMC amounts. We hypotheize that a high amount of growth factors released from platelets are more suitable for regeneration of high vascularized tissues such as bone [35] and skin. Schweitzer et al. described SCX as a differentiation-associated transcription factor expressed in progenitors and tendon tissue cells. It was found to be an important factor in early tendon formation [36, 37]. Col1A1 is important for the stability of tendon tissue. With immunohistochemistry we were able to assess the effect of PMC on tenocytes. The treatment of tenocytes with $1 \%$ PMC leads to increased SXC expression. There was no significant difference in TNMD expression after either treatment or non-treatment of tenocytes with PMC. TNMD is seen as an important regulator of tenocyte proliferation and involvement in collagen fibril maturation [38].

The distribution of types I and III collagen is critical for the tensil strength of tendons [39]. We could demonstrate that a low amount of PMC leads to increased typ I collagen synthesis in monolyer culture. The mechanical properties of tendons cannot be determined in monolayer cultivation. Furthermore, tenocytes in monolayer culture display an unstable phenotype and tend to de-differentiate [40]. Additional experiments in three-dimensional cultures are nessecary to analyse effects of PMC on phenotype differentiation and function of these cells, as well as the organization of the synthetized collagen network.

It is possible to identify tenocytes in vitro with immunohistochemistry; in culture mediums of higher passages, tenocytes display a tendency toward phenotypic drift and dedifferentiation [41-43].

We were able to demonstrate that PMC can be an additional source of the already various expression of endogenous growth factors and cytokines in tendon healing.

\section{Conclusions}

As previously discussed, between three and five million people worldwide are afflicted with tendon and ligament injuries every year. Achilles tendinopathy is often related to specific sport injuries caused by inappropriate biomechanical stress. Here we provide evidence that PMC exerts a biological effect on tenocytes by promoting tenocyte growth and by upregulating tenogen specific markers. We hypothesize that low concentrations of PMC can accelerate the tendon healing and reduce both scar formation as well as the typically high risk of recurrence upon tendon loading. We intend to explore this question by investigating the effect of platelet mediators on tenocytes under nonphysiological strain conditions in a bioreactor. Furthermore, long-term in vitro studies should investigate the effect of PMC treatment on ECM components. In vivo studies will be necessary in order to confirm the results.

\section{Abbreviations}

BMP, bone morphogenetic protein; BSA, bovine serum albumin; C, grad celsius; COL1A1, type I collagen A 1; DMEM, Dulbecco's modified Eagle's medium; ELISA, enzyme linked immunosorbent assay; FCS, fetal calf serum; G, gravitational; h, hour; $H$, human; IF, immunofluorescence; IL, interleukin; min, minute; MMP, matrix metalloproteinase; MSC, mesenchymal stem cells; PBS, phosphate buffered saline; PDGF-BB, platelet derived growth factor BB; PMC, platelet mediator concentrate; PPP, platelet poor plasma; PRP, platelet rich plasma; PSF, penicillin streptomycin Fungizone; SCX, scleraxis; SEM, standard error; TDSC, tendon derived stem cell; TGF-ß, transforming growth factor beta; TNF, tumor necrosis factor; TNMD, tenomodulin; VEGF, vascular endothelial growth factor

\section{Acknowledgements}

The ATR ${ }^{\oplus}$ kits used in this study were sponsored by Curasan AG Kleinostheim, Germany.

The study was supported by the German Society for Orthopaedics and Orthopaedic Surgery (DGOOC); by MSD (SHARP \& DOHME GmbH); by a grant from the Interdisciplinary Centre for Clinical Research (IZKF, T9-5 and T11-3); ERS, BOOST OPBF071 within the Faculty of Medicine at the RWTH University of Aachen; by the German Research Foundation (Deutsche Forschungsgemeinschaft), grants DR449/ 2-1, PU214/5-2, VA 220/2-1, PU214/4-2, and PU214/3-2; and by a grant from the Medical Faculty of Kiel (FoFö). We would like to thank Dr. Nisreen Kweider and Mrs. Sara tabea Schneider for performing the scoring in this work. We thank Alexander Slowik M.Sc. for advice in immunofluorescence analyses. Also thank Mrs. Sara Nuesser and Mr. André Doering for providing Achilles tendon tissue (pursuant to declarations of consent).

\section{Funding}

The ATR ${ }^{\oplus}$ kits used in this study were sponsored by Curasan AG Kleinostheim, Germany.

The study was supported by the German Society for Orthopaedics and Orthopaedic Surgery (DGOOC); by MSD (SHARP \& DOHME GmbH); by a grant from the Interdisciplinary Centre for Clinical Research (IZKF, T9-5 and T11-3); ERS, BOOST OPBF071 within the Faculty of Medicine at the RWTH University of Aachen; by the German Research Foundation (Deutsche Forschungsgemeinschaft), grants DR449/2-1, PU214/5-2, VA 220/2-1, PU214/4-2, and PU214/3-2; and by a grant from the Medical Faculty of Kiel (FoFö).

\section{Availability of data and materials}

The raw data can be requested.

\section{Authors' contributions}

EA: conceived and carried out the experiments, data analysis, data interpretation, generation of figures, writing of the manuscript. TN: participated in the Immunofluorescence staining and analysed the IF data. ABayer: participated in the delivery of tendon tissues, data interpretation. APrescher: participated in the delivery of tendon tissues, participated in the study design, final approval of the manuscript. SL: participated in the study design and helped to collect the blood samples, final approval of the manuscript. SN: participated in the delivery of tendon tissues and participated in the study design. HJ: final approval of the manuscript. CJ: 
helped by application of ATR kit. WDH: helped by coordination the study and final approval of the manuscript. HF: drafting the article or revising it critically, final approval of the manuscript. MStoffel: final approval of the manuscript. MShakibaei: devised in tenocytes cultivation, data interpretation, drafting the article or revising it critically, final approval of the manuscript. TP: participated in study design, data interpretation, drafting the article or revising it critically, final approval of the manuscript. MT: study design, generation of figures, data analysis, data interpretation, drafting the article or revising it critically, final approval of the manuscript. All authors were participated in literature research, made important suggestions and intellectual content for manuscript drafting, read and approved the final manuscript.

\section{Competing interests}

The authors declare that they have no competing interests.

\section{Consent for publication}

Not applicable.

\section{Ethics approval and consent to participate}

Blood prepatations were obtained by healthly anonymously donors, in accordance with the current German ethics laws (EK116/10 local ethical board RWTH Aachen University).

All animal care and experimental procedures were formally approved by the Review Board for the Care of Animal Subjects of the district government (North Rhine-Westphalia, Germany). All studies involving animals are reported in accordance with the ARRIVE guidelines for reporting experiments involving animals.

\section{Author details}

'Department of Anatomy and Cell Biology, RWTH Aachen University, Wendlingweg 2, D-52074 Aachen, Germany. ${ }^{2}$ Department of Prosthodontics and Biomaterials Centre of Implantology, Medical Faculty, University Hospital of RWTH Aachen University, Aachen, Germany. ${ }^{3}$ Department of Heart and Vascular Surgery, University Hospital of Schleswig-Holstein Campus Kiel, Kiel, Germany. ${ }^{4}$ Department of Molecular and Cellular Anatomy, RWTH Aachen University, Aachen, Germany. ${ }^{5}$ Department of Trauma Surgery, University Medical Center Schleswig-Holstein Kiel Campus, Kiel, Germany. ${ }^{6}$ Department of Orthopaedic Surgery, University Hospital of RWTH Aachen University, Aachen, Germany. ${ }^{7}$ Curasan AG, Kleinostheim, Germany. ${ }^{8}$ Department of Dental Materials and Biomaterials Research, University Hospital of RWTH Aachen University, Aachen, Germany. ${ }^{9}$ Institute of General Mechanics, RWTH Aachen University, Aachen, Germany. ${ }^{10}$ Institute of Anatomy LudwigMaximilians University Munich, Munich, Germany.

Received: 19 February 2016 Accepted: 12 July 2016

Published online: 22 July 2016

\section{References}

1. Bullough R, Finnigan T, Kay A, Maffulli N, Forsyth NR. Tendon repair through stem cell intervention: cellular and molecular approaches. Disabil Rehabil. 2008;30(20-22):1746-51.

2. Abate M, Schiavone C, Salini V, Andia I. Occurrence of tendon pathologies in metabolic disorders. Rheumatology. 2013;52(4):599-608.

3. Josza L, Kannus P. Human tendons. London: Human Kinetics; 1998.

4. Petersen W, Pufe T, Pfrommer S, Tillmann B. Overload damage to the Achilles tendon: the importance of vascularization and angiogenesis. Orthopade. 2005;34(6):533-42.

5. Pufe T, Petersen W, Tillmann B, Mentlein R. The angiogenic peptide vascular endothelial growth factor is expressed in foetal and ruptured tendons. Virchows Arch. 2001;439(4):579-85.

6. Pufe T, Petersen WJ, Mentlein R, Tillmann BN. The role of vasculature and angiogenesis for the pathogenesis of degenerative tendons disease. Scand J Med Sci Sports. 2005;15(4):211-22.

7. Voleti PB, Buckley MR, Soslowsky LJ. Tendon healing: repair and regeneration. Annu Rev Biomed Eng. 2012;14:47-71.

8. Goldin M, Malanga GA. Tendinopathy: a review of the pathophysiology and evidence for treatment. Phys Sportsmed. 2013;41(3):36-49.

9. Soroceanu A, Sidhwa F, Aarabi S, Kaufman A, Glazebrook M. Surgical versus nonsurgical treatment of acute Achilles tendon rupture: a meta-analysis of randomized trials. J Bone Joint Surg Am. 2012;94(23):2136-43.
10. Cummings SH, Grande DA, Hee CK, Kestler HK, Roden CM, Shah NV Razzano P, Dines DM, Chahine NO, Dines JS. Effect of recombinant human platelet-derived growth factor-BB-coated sutures on Achilles tendon healing in a rat model: a histological and biomechanical study. J Tissue Eng. 2012; 3(1):2041731412453577.

11. Schulze-Tanzil G, Al-Sadi O, Wiegand E, Ertel W, Busch C, Kohl B, Pufe T. The role of pro-inflammatory and immunoregulatory cytokines in tendon healing and rupture: new insights. Scand J Med Sci Sports. 2011;21(3):337-51.

12. Chen HS, Chen YL, Harn HJ, Lin JS, Lin SZ. Stem cell therapy for tendon injury. Cell Transplant. 2013;22(4):677-84.

13. Baksh N, Hannon CP, Murawski CD, Smyth NA, Kennedy JG. Platelet-rich plasma in tendon models: a systematic review of basic science literature. Arthroscopy. 2013;29(3):596-607.

14. Solchaga LA, Bendele A, Shah V, Snel LB, Kestler HK, Dines JS, Hee CK. Comparison of the effect of intra-tendon applications of recombinant human platelet-derived growth factor-BB, platelet-rich plasma, steroids in a rat achilles tendon collagenase model. J Orthop Res. 2014;32(1):145-50.

15. Sadoghi $P$, Rosso C, Valderrabano V, Leithner A, Vavken $P$. The role of platelets in the treatment of Achilles tendon injuries. J Orthop Res. 2013; 31(1):111-8

16. Tohidnezhad M, Varoga D, Wruck CJ, Brandenburg LO, Seekamp A, Shakibaei M, Sonmez TT, Pufe T, Lippross S. Platelet-released growth factors can accelerate tenocyte proliferation and activate the anti-oxidant response element. Histochem Cell Biol. 2011;135(5):453-60.

17. Mei-Dan O, Lippi G, Sanchez M, Andia I, Maffulli N. Autologous platelet-rich plasma: a revolution in soft tissue sports injury management? Phys Sportsmed. 2010;38(4):127-35.

18. Schmolz M, Stein GM, Hübner WD. An innovative, centrifugation-free method to prepare human platelet mediator concentrates showing activities comparable to platelet-rich plasma. Wounds. 2011;23(6):171-82.

19. Wruck CJ, Wruck A, Brandenburg LO, Kadyrov M, Tohidnezhad M, Pufe T. Impact of Nrf2 on esophagus epithelium cornification. Int J Dermatol. 2011:50(11):1362-5.

20. Tohidnezhad M. Die Wirkmechanismen von Plättchenreichem Plasma (PRP) in Zellen des Bewegungsapparates. University library: RWTH Aachen University library. 2014. p. 4136

21. Schindelin J, Arganda-Carreras I, Frise E, Kaynig V, Longair M, Pietzsch T, Preibisch S, Rueden C, Saalfeld S, Schmid B, Tinevez JY, White DJ, Hartenstein V, Eliceiri K, Tomancak P, Cardona A. Fiji: an open-source platform for biological-image analysis. Nat Methods. 2012;9(7):676-82.

22. Dhillon MS, Behera P, Patel S, Shetty V. Orthobiologics and platelet rich plasma. Indian J Orthop. 2014;48(1):1-9.

23. Zumstein MA, Rumian A, Lesbats V, Schaer M, Boileau P. Increased vascularization during early healing after biologic augmentation in repair of chronic rotator cuff tears using autologous leukocyte- and platelet-rich fibrin (L-PRF): a prospective randomized controlled pilot trial. J Shoulder Elbow Surg. 2014;23(1):3-12.

24. Engebretsen L, Steffen K, Alsousou J, Anitua E, Bachl N, Devilee R, Everts P, Hamilton B, Huard J, Jenoure $P$, et al. IOC consensus paper on the use of platelet-rich plasma in sports medicine. Br J Sports Med. 2010;44(15):1072-81.

25. Castillo TN, Pouliot MA, Kim HJ, Dragoo JL. Comparison of growth factor and platelet concentration from commercial platelet-rich plasma separation systems. Am J Sports Med. 2011;39(2):266-71.

26. Lopez C, Carmona JU, Giraldo CE, Alvarez ME. Bacteriostatic effect of equine pure platelet-rich plasma and other blood products against methicillinsensitive Staphylococcus aureus. An in vitro study. Vet Comp Orthop Traumatol. 2014;27(5):372-8.

27. Wojciak B, Crossan JF. The accumulation of inflammatory cells in synovial sheath and epitenon during adhesion formation in healing rat flexor tendons. Clin Exp Immunol. 1993:93(1):108-14.

28. Wojciak B, Crossan JF. The effects of T cells and their products on in vitro healing of epitenon cell microwounds. Immunology. 1994;83(1):93-8.

29. Kaux JF, Janssen L, Drion P, Nusgens B, Libertiaux V, Pascon F, Heyeres A, Hoffmann A, Lambert C, Le Goff C, et al. Vascular Endothelial Growth Factor-111 (VEGF-111) and tendon healing: preliminary results in a rat model of tendon injury. Muscles Ligaments Tendons J. 2014;4(1):24-8.

30. Ackermann PW, Domeij-Arverud E, Leclerc P, Amoudrouz P, Nader GA. Antiinflammatory cytokine profile in early human tendon repair. Knee Surg Sports Traumatol Arthrosc. 2013;21(8):1801-6.

31. Andersen $M B$, Pingel J, Kjaer $M$, Langberg $H$. Interleukin-6: a growth factor stimulating collagen synthesis in human tendon. J Appl Physiol (Bethesda, Md: 1985). 2011;110(6):1549-54. 
32. Eliasson P, Andersson T, Aspenberg P. Rat Achilles tendon healing: mechanical loading and gene expression. J Appl Physiol (Bethesda, Md: 1985). 2009;107(2):399-407.

33. Lui PP, Wong Y. Higher BMP/Smad sensitivity of tendon-derived stem cells (TDSCs) isolated from the collagenase-induced tendon injury model: possible mechanism for their altered fate in vitro. BMC Musculoskelet Disord. 2013;14:248.

34. Bi Y, Ehirchiou D, Kilts TM, Inkson CA, Embree MC, Sonoyama W, Li L, Leet Al, Seo BM, Zhang L, et al. Identification of tendon stem/progenitor cells and the role of the extracellular matrix in their niche. Nat Med. 2007;13(10):1219-27.

35. Tohidnezhad M, Wruck CJ, Slowik A, Kweider N, Beckmann R, Bayer A, Houben A, Brandenburg LO, Varoga D, Sonmez TT, et al. Role of plateletreleased growth factors in detoxification of reactive oxygen species in osteoblasts. Bone. 2014;65:9-17.

36. Schweitzer R, Chyung JH, Murtaugh LC, Brent AE, Rosen V, Olson EN, Lassar A, Tabin CJ. Analysis of the tendon cell fate using Scleraxis, a specific marker for tendons and ligaments. Development (Cambridge, England). 2001; 128(19):3855-66.

37. Murchison ND, Price BA, Conner DA, Keene DR, Olson EN, Tabin CJ, Schweitzer R. Regulation of tendon differentiation by scleraxis distinguishes force-transmitting tendons from muscle-anchoring tendons. Development (Cambridge, England). 2007;134(14):2697-708.

38. Docheva D, Hunziker EB, Fassler R, Brandau O. Tenomodulin is necessary for tenocyte proliferation and tendon maturation. Mol Cell Biol. 2005;25(2):699-705.

39. Williams IF, McCullagh KG, Silver IA. The distribution of types I and III collagen and fibronectin in the healing equine tendon. Connect Tissue Res. 1984;12(3-4):211-27.

40. Schulze-Tanzil G, Mobasheri A, Clegg PD, Sendzik J, John T, Shakibaei M. Cultivation of human tenocytes in high-density culture. Histochem Cell Biol. 2004;122(3):219-28.

41. Abrahamsson SO, Lundborg G, Lohmander LS. Segmental variation in microstructure, matrix synthesis and cell proliferation in rabbit flexor tendon. Scand J Plast Reconstr Surg Hand Surg. 1989;23(3):191-8.

42. Bernard-Beaubois K, Hecquet C, Houcine O, Hayem G, Adolphe M. Culture and characterization of juvenile rabbit tenocytes. Cell Biol Toxicol. 1997; 13(2):103-13.

43. Yao L, Bestwick CS, Bestwick LA, Maffulli N, Aspden RM. Phenotypic drift in human tenocyte culture. Tissue Eng. 2006;12(7):1843-9.

\section{Submit your next manuscript to BioMed Central and we will help you at every step:}

- We accept pre-submission inquiries

- Our selector tool helps you to find the most relevant journal

- We provide round the clock customer support

- Convenient online submission

- Thorough peer review

- Inclusion in PubMed and all major indexing services

- Maximum visibility for your research

Submit your manuscript at www.biomedcentral.com/submit

) Biomed Central 